\title{
Knowledge and Use of Micronutrient Supplementation among Pregnant Women Attending Antenatal Visit at Federal Medical Centre, Bida, Niger State, Nigeria
}

\author{
Dr Abraham Dare Ajayi, Gotodok Kopdima Hosea, Gaknung Bonji Kopdimma, Daniel Cletus \\ Okpe, Udeh Peter Adah, AziBulus Samuel, Dauda Esther Dung, Tsado Dufya Serah
}

\begin{abstract}
Background -Approximately two billion people, the majority being women and young children, are affected, by micronutrient deficiencies, with even higher rates during pregnancy causing adverse outcome in mother and child. This adverse effect can be mitigated by nutritional interventions like micronutrient supplementation.

Aim of the study

This study aim at assessing knowledge and use of micronutrient supplements among pregnant women attending Federal Medical Centre, Bida. This is a descriptive cross-sectional study, comprising of a sample size of 381 respondents. A structured questionnaire was utilized in data collection which lasted for six weeks period and data analysis was done using SPSS version 22

Result
\end{abstract}

The findings revealed that most (67.9) of the respondents were between the ages of $21-30,46.7 \%$ were $4-6$ gestational age, $49.6 \%$ were secondary certificate holders, $41.5 \%$ were traders while majority $(53.5 \%)$ practice Islam. majority $(91.3 \%)$ of the respondents are aware of routine micronutrient supplementation in pregnancy with Iron (fersolate) $(\mathbf{9 4 . 4 \%})$, Folic acid $(91.8 \%)$, Vitamin D $(52.5 \%)$, Vitamin A $(80.1 \%)$ and Vitamin $C(86.6 \%)$ as routine drugs (micronutrients) in pregnancy. Most $(\mathbf{7 4 . 0 \%})$ of the respondents use routine micronutrients and $(65.6 \%)$ use them on daily basis. Fear of side effects of drugs $(\mathbf{5 2 . 5 \%})$, cultural belief $(\mathbf{7 8 . 7 \%})$, forgetfulness $(\mathbf{5 0 . 2 \%})$, tired of taking the routine drugs $\mathbf{( 7 6 . 1 \% )}$ and attitudes of health care providers $(\mathbf{8 6 . 8 \%})$ were the factors as reported by the respondents that affects their use of routine drugs supplementation in pregnancy.

Conclusion

The study concludes that significant knowledge of routine micronutrient supplementation in pregnancy andadherence to the use of the routine micronutrient is key to prevention of deficiencies(anemia, spina bifida low birth weight among others) associated with non-adherence.it was recommended that

Dr Abraham Dare Ajayi, Department of Nursing Science, Faculty of Health Science and Technology, University of Jos

Gotodok Kopdima Hosea, Department of Nursing Science, Faculty of Health Science and Technology, University of Jos

Gaknung Bonji Kopdimma, Department of Nursing Science, Faculty of Health Science and Technology, University of Jos

Daniel, Cletus Okpe, Department of Nursing Science, Faculty of Health Science and Technology, University of Jos

Udeh Peter Adah, Department of Nursing Science, Faculty of Health Science and Technology, University of Jos

Azi Bulus Samuel, School of Nursing, Vom, Plateau State.

Dauda Esther Dung, School of Midwifery, Jos, Plateau State.

Tsado Dufya Serah, Department of nursing sciences, National Open University Nigeria (NOUN) Abuja
Health personnel should place more emphasize on explaining the danger associated with non-compliance to the use of routine micronutrients supplements on the developing fetus and baby during health education at antenatal visit, Health personnel should be friendly to women on antenatal visit as this will enhance their use of routine micronutrients supplements, and the Government should always ensure that routine micronutrient supplements are readily available, accessible and affordable to all women of child bearing age.

Index Terms - knowledge, use, micronutrient, supplements, pregnant women, factors.

\section{INTRODUCTION}

\section{Background to the Study}

The nutritional status of a woman before and during pregnancy is important for a healthy pregnancy outcome. However nutritional deficiencies are widely prevalent globally and contribute significantly to high rates of morbidity and mortality among mothers, infants and children in developing countries. More than one third of child deaths in some developing countries are thought to be attributable to maternal and child under nutrition (Black, Allen, Bhutta, Caulfield, de Onis, Ezzati, 2008). The prevalence of maternal under nutrition - that is, a BMI of less than $18.5 \mathrm{~kg} / \mathrm{m}^{2}$ ranges from 10 to $19 \%$ in most countries with more than $20 \%$ of women in sub-Saharan Africa, South central and Southeastern Asia, and Yemen reported to have a BMI of less than $18.5 \mathrm{~kg} / \mathrm{m}^{2}$ (Thirukkanesh\&Zahara, 2010). This scenario has adverse effects on pregnancy outcome and increases the risk of maternal and infant morbidity and mortality.

Maternal malnutrition is a modifiable risk factor of public health importance. Prevention of malnutrition including micronutrient deficiency therefore has been integrated into efforts to prevent adverse birth outcomes, particularly among economically developing/low-income populations (Kawai, Spiegelman, Shankar \&Fawzi, 2011). Poor nutritional status of mothers during pregnancy has direct and indirect consequences on the health of mothers and that of their children. The nutritional status of a mother therefore is important, both as an indicator of her overall health and as a predictor of pregnancy outcome for both mother and child (Elshibly\&Schmalisch, 2008;Khoushabi\&Saraswathi, 2010). Though micronutrients are nutrients needed only in very small quantities, they are essential for normal physiological 
function, growth and development. According to Taddese\&Henok (2013),micronutrient deficiencies result from inadequate intake of meat, fruits and vegetables, but infections can also be a cause.

Globally, approximately two billion people, the majority being women and young children, are affected, by micronutrient deficiencies, with even higher rates during pregnancy (WHO, 2014). This is especially so for adolescent pregnancies and women of lower economic or minority status in low and middle-income economic settings (Darnton-Hill, 2012). These micronutrient deficiency states exist in Nigeria and pose a public health problem (National Demographic Health Survey, 2013). Although iron-deficiency anemia is recognized as an important risk factor for maternal and perinatal mortality globally, emerging evidence suggests that micronutrients such as vitamin B12, folic acid, vitamin D and selenium may also be important for maternal, infant and child outcomes (Darnton-Hill \&Mkparu, 2015). Other micronutrients that are important for maintaining the mother and the fetus through the period of pregnancy include Vitamin $\mathrm{C}$ and Calcium. Their deficiencies also put the life of the mother and the fetus at risk.

De Ver Dye (2015) asserts that micronutrient supplementation knowledge is associated with micronutrient supplement consumption in a dose-response manner over pregnancy with increasing knowledge associated with increased MNS consumption. Similarly Gebremedhin, Samuel, Mamo,Moges\&Assefa(2014) observed that promoting the knowledge of women on anemia are essential strategies for improving the utilization of iron supplements for the prevention of anaemia. This strategy is considered effective in enhancing compliance to supplementation of other micronutrients other than iron. Improved knowledge may translate to a positive attitude further encouraging compliance to healthy behaviors such as micronutrient supplementation in pregnancy.

A study carried by Desta M, Kassie B, Chanie H, Mulugeta H, Yirga T, Temesgen H, Leshargie CT, Merkeb Y (2019) on adherence of iron and folic acid supplementation and determinants among pregnant women in Ethiopia: a systematic review and meta-analysis with a total of 16,818 pregnant women showed that the pooled national level iron and folic acid supplementation's adherence were $46.15 \%$. The highest adherence was observed in Addis Abeba, 60\% followed by Tigray, $58.9 \%$. Women who received supplemental information, who had good knowledge, began the ANC visit before 16 weeks, and had $\geq 4$ ANC visits were more likely adhere to the supplementation. Fear of side effects and forgetfulness were the major barriers of adherence of the supplementations.

Roy, Evers and Campbell (2012) studied dietary supplement use and iron, zinc and folate intake from both food and supplement sources in 2019 pregnant women in London, Ontario. Their findings showed that most women took a multivitamin supplement, and many women took folic acid and iron supplements; however, one-fifth of the sample did not take any supplements providing any of the three micronutrients. Despite being of a higher socio-economic status overall, significant proportions of the cohort ranked below the recommended dietary allowance values for iron, zinc, and folate.

Bekele, Gedefaw\&, Alemtsehay (2015) carried out a study to determine the factors associated with compliance of prenatal iron folate supplementation among women in Mecha district, Western Amhara, Ethiopia, Community based cross sectional study. Results revealed that Only $20.4 \%$ of participants were compliant with iron foliate supplementation, multivariable analysis, age of the mother, educational status of the mother, knowledge of anaemia and iron folate tablets, and history of anaemia during pregnancy were significantly associated with compliance to iron folate supplementation $(\mathrm{P}<.05)$. Also belief that too many tablets would harm the baby and fear of side effects were the major reasons given for noncompliance.

Ugwu, Olibe, Obi, \& $\underline{\text { Ugwu }}$ (2014) evaluated the determinants of compliance to iron supplementation among pregnant women in Enugu, Southeastern Nigeria using a questionnaire-based cross-sectional descriptive design in a sample of 302 eligible pregnant women receiving antenatal care at the University of Nigeria Teaching Hospital, findings revealed that $\operatorname{most}(76.3 \%)$ of them are aware of iron supplementation however with adherence rate of $65.9 \%$. The major impediments to compliance to iron supplementation included gastrointestinal side effects of iron supplements (41.7\%), non-affordability of iron supplements (28.3\%), and forgetfulness $(15.0 \%)$ among the antenatal mothers.

\section{STATEMENT OF PROBLEM}

Good nutrition during pregnancy is one of the most significant contributors to optimal maternal and fetal health. However, poor maternal and newborn health and nutrition remain significant contributors to the burden of disease and mortality (WHO, 2013).

These nutrient deficiencies are generally found in low-socio-economic populations, where they are more likely to involve multiple rather than single deficiencies (Ugwa, 2015); thereby predisposing pregnant women in these settings to micronutrient deficiency.

Studies of micro nutrient deficiencies outside and within Nigeria has revealed that considerable proportion of pregnant women still suffer deficiencies of micronutrient such as iron, folic acid, calcium and vitamin C. (Afam\&Nkwam, 2012; Ogbodo, 2012; Oguizu, 2015). Interventions aimed at preventing micronutrient deficiency in pregnancy include supplementation, fortification of staple foods with micronutrients, health and nutrition education, control of parasitic infections, and improvement in sanitation. Supplementation with micronutrients is a well-established intervention but the coverage and impact has been poor despite clear WHO recommendations for both anaemic and non-anaemic pregnant women and by national bodies (Darnton-Hill, 2015).

Despite routine micronutrient supplementation being an integral aspect of antenatal care given to pregnant women in Nigeria, the researcher observed that most pregnant women usually come up with pre-eclampsia, pre-term birth, miscarriage, low birth as well as anaemic. This study is therefore designed to investigate the knowledge and the use 
of micronutrient supplements among pregnant women in Federal Medical Centre, Bida State, Nigeria.

\section{Objectives}

The specific objectives are to:

1. Assess the knowledge of micronutrient supplementation during pregnancy among pregnant women at Federal Medical Centre, Bida.

2. Evaluate the use of micronutrient supplements during pregnancy among pregnant women at Federal Medical Centre, Bida.

3. Determine the factors affecting the use of micronutrient supplements during pregnancy at Federal Medical Centre, Bida.

\section{Research Questions}

1. What is the level of knowledge about of micronutrients supplementation during pregnancy?

2. What is the level of use of micronutrient supplements among pregnant women at Federal Medical Centre, Bida?

3. What are the factors affecting the use of micronutrient supplements among pregnant women at Federal Medical Centre, Bida?

\section{METHOD}

\section{Research Design}

A cross sectional descriptive design was used for the study. This design is considered appropriate as it has been successfully used in similar studies such as those by Oriji,

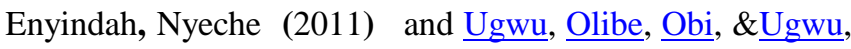
(2014).

\section{Area of Study}

The study area is Federal Medical Centre, Bida. The hospital was established by an agreement concluded on April 3, 1997 between the Federal Government of Nigeria and the Government of Niger State. This agreement culminated in the upgrading of the former General Hospital, Bida unto a tertiary health facility.

\section{Population of Study}

The population of the study includes all pregnant women attending antenatal visit in their six weeks and the total number of women attending antenatal in the six weeks is 3947.

\section{Sample}

A sample size of 352 respondents was used. This sample was determined using power analysis. At 95\% Confidence interval and 5\% margin of error, a sample size of 352 was calculated. As the researcher anticipates a $10 \%$ attrition rate, the sample size will be adjusted to 388 .

A purposive sampling technique was used to select the sample for the study. All the women seen in each facility were selected until the total number assigned to the facility was attained.

\section{Instrument for Data Collection}

A self-developed structured questionnaire with closed ended questions was used as an instrument for data collection. The questionnaire consists of four sections: A, B, $\mathrm{C}$ and $\mathrm{D}$ respectively.

\section{Validity/ Reliability of the Instrument}

The instrument was validated through subjecting it to expert judgment by the researcher's supervisor and two (2) senior lecturers in the Department of Nursing. AndPilot testing of the instrument was done to establish the reliability of the instrument. It was a single administration and the data generated were analyzed using cronchbach correlation coeeficient. A reliability index of 0.87 was obtained signifying that the instrument is reliable for data collection.

\section{Procedure for Data Collection}

The researchers together with five (5) research assistants administered the questionnaires to the respondents at Federal Medical Centre, Bida. They were instructed on the purpose of the study and how to administer the questionnaire. Data were collected on the spot from the pregnant women who met the inclusion criteria before or after they have seen the doctor. Questionnaires were administered individually and women who were not able to read the questions were assisted. Data collection lasted for a period of 6 weeks.

\section{Data Analysis}

Data collected were analyzed using statistical package for social science (SPSS) version 22, and were presented using frequency tables and percentages.

\section{Ethical Consideration}

An introductory letter was collected from the nursing department; university of Jos.

An ethical clearance letter was collected for permission to carry out the study from the management ofFederal Medical Centre, Bida.

Informed consent was obtained from the subjects before administering the questionnaires and Confidentiality and anonymity of their information was maintained.

\section{Result}

The data generated from the study are presented using Tables according to the research objectives. Out of 388 copies of the questionnaire distributed, 381 were valid for data analysis, giving a return rate of $98 \%$. 


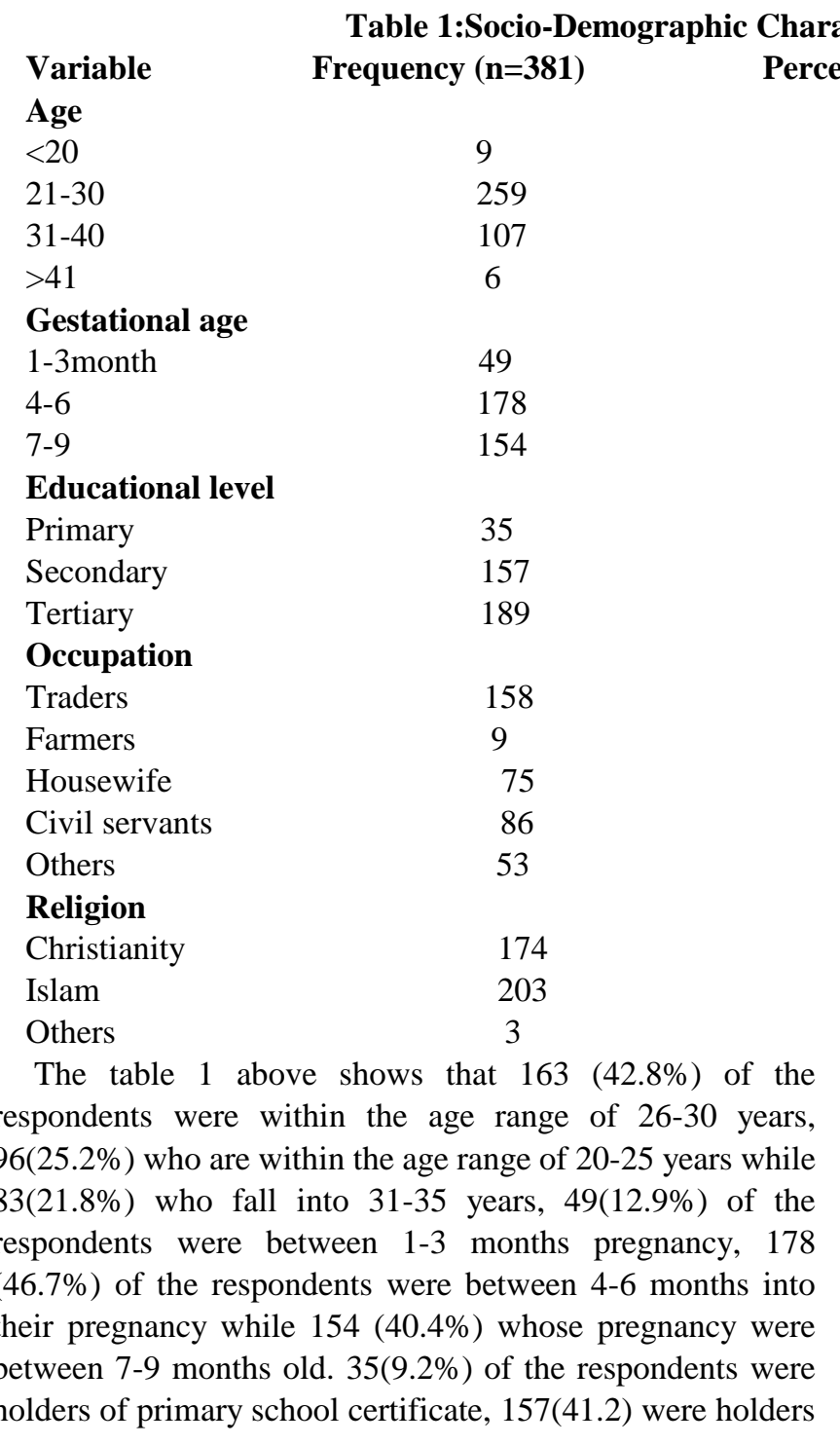

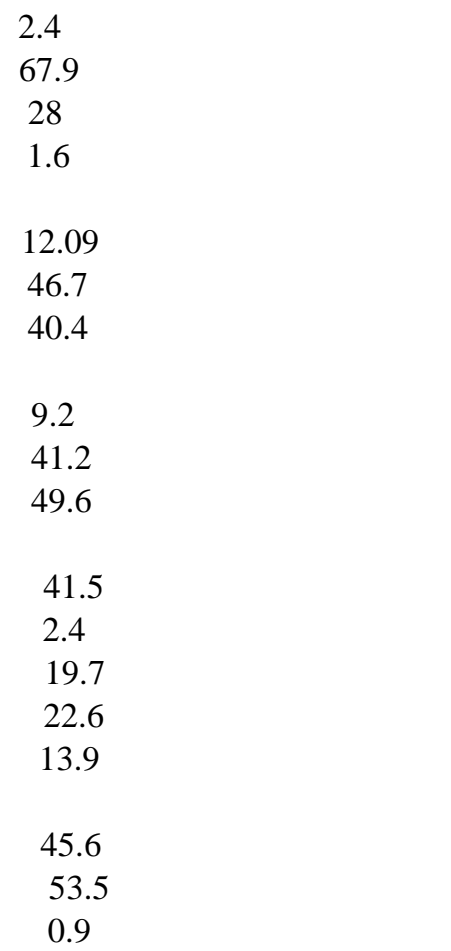

of secondary certificate while $189(49.6 \%)$ were holders of tertiary certificate. $158(41.5)$ of the respondents were traders, 9(2.4) were farmers, 75(19.7) were housewife, 86(22.6) were civil servants while 53(13.9) were doing other work. 174(45.6) of the respondents were Christian, 204(53.5) were islam while $3(0.9)$ practice other religion.

Table 2: Routine micronutrient knowledge among pregnant women

Items

Have you heard about routine micronutrient supplement in pregnancy?348(91.3\%)33(8.7\%) Where did you hear about that?

Family relation

Friends

Mass media

Hospital $90(23.6 \%)$

Traditional birth attendant 0

\section{Routine drugs}

Iron(fersolate)

$\begin{array}{ll}360(94.4 \%) & 21(5.6 \%) \\ 350(91.8 \%) & 31(8.2 \%) \\ 150(39.4 \%) & 231(60.6 \%) \\ 130(34.1 \%) & 251(65.9 \%) \\ 200(52.5 \%) & 181(47.5 \%) \\ 305(80.1 \%) & 77(19.9 \%) \\ 330(86.6 \%) & 51(14.4 \%)\end{array}$

Folic acid

Calcium

Iodine

Vitamin D

Vitamin A

$330(86.6 \%) \quad 51(14.4 \%)$

Vitamin C 
Table 2 above shows that $348(91.3 \%)$ of the respondents heard about routine micronutrients supplementations while $33(8.7 \%)$ do not, $100(26.2 \%)$ heard it from family relation, $71(18.6 \%)$ heard from friends, $120(31.6 \%)$ heard from mass media, and 90(23.6\%) heard from the hospital. 360(94.4\%) agree that iron is one of the routine drug supplement while $21(5.6 \%)$ do not, $350(91.8 \%)$ agree that folic acid is one of the drugs while $31(8.2 \%)$ do not, $150(39.4 \%)$ agree that calcium is one of the drugs while $231(60.6 \%)$ do not, $130(34.1 \%)$ agree that iodine is one of the drugs while $251(65.9 \%)$ do not, $200(52.5 \%)$ agree that vitamin D is one of the drugs while $181(47.5 \%)$ do not, $305(80.1 \%)$ agree that vitamin $\mathrm{A}$ is one of the drugs while $77(19.9 \%)$ do not and $330(86.6 \%)$ agree that vitamin $\mathrm{C}$ is one of the drugs while $51(14.4 \%)$ do not.

\section{Table 3: use of routine micronutrient supplements by pregnant women}

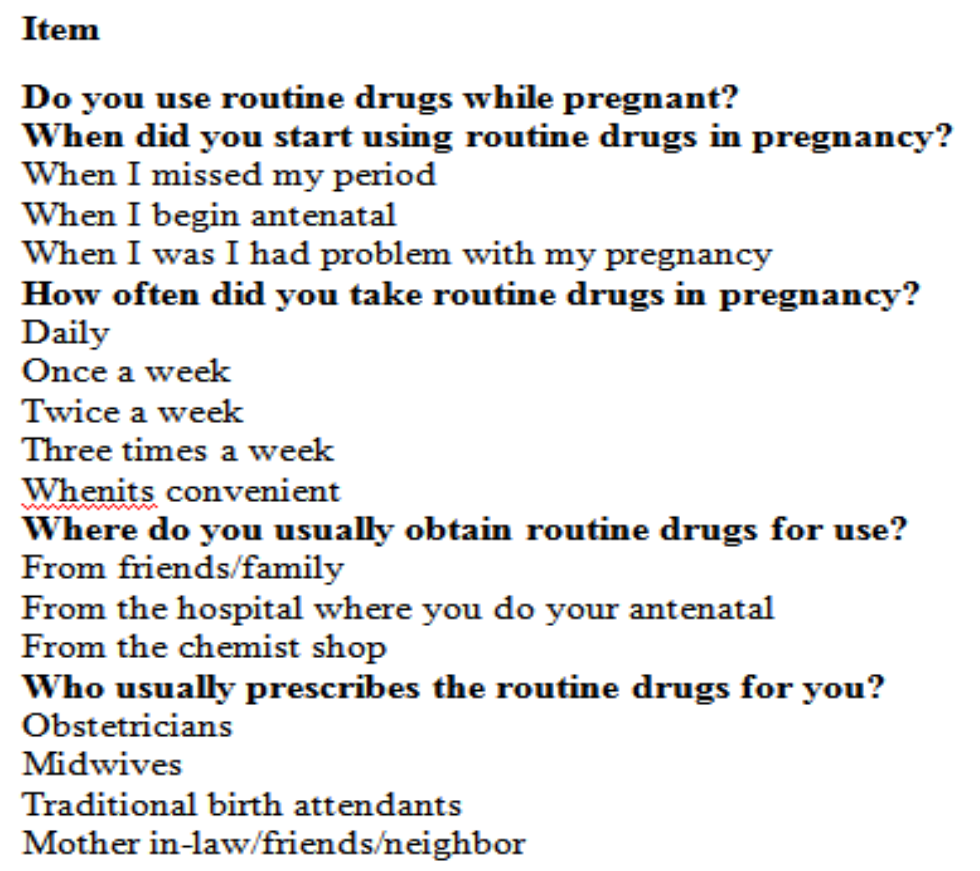

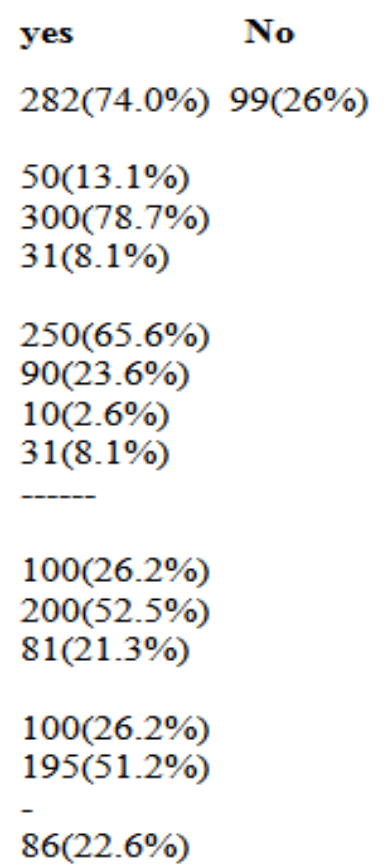

week, $10(2.6 \%)$ use routine drugs twice a week, $31(8.1 \%)$ and use routine drugs three times a week. 100(26.2\%) admit that they obtain their routine drugs from friends/family, $200(52.5 \%)$ obtain from their hospital of antenatal care, and $81(21.3 \%)$ obtain from the chemist.
Table 3 above shows that $282(74.0 \%)$ use routine micronutrient supplement while $99(26 \%)$ do not, 50(13.1\%) use routine drugs when they missed their period, $300(78.7 \%)$ use routine drugs when the begin antenatal and 31(8.1\%) use when they have problem with their pregnancy. 250(65.6\%) used routine drugs daily, $90(23.6 \%)$ use routine drugs once a
Table 4: factors affecting the use of micronutrient supplementation among pregnant

\section{Factors}

Fear of Side effects

Distance from the health facilities

Cultural belief

Forgetfulness

Fear of taking too many tables

Tired of taking the routine drugs

Attitudes of health care providers yes

No

$\begin{array}{lc}200(52.5 \%) & 181(47.5 \%) \\ 100(26.2 \%) & 281(73.8 \%) \\ 300(78.7 \%) & 81(21.3 \%) \\ 171(50.2 \%) & 190(49.8 \%) \\ 50(13.1 \%) & 331(86.9 \%) \\ 290(76.1 \%) & 91(23.9 \%) \\ 331(86.8 \%) & 50(13.2 \%)\end{array}$


Table 4 above shows that $200(52.5 \%)$ of the respondents agree that side effects of the drugs affects them while $181(47.5 \%)$ did not, $100(26.2 \%)$ said distance from health facilities affects them while $281(73.8 \%)$ do not agree, $300(78.7 \%)$ agree that cultural belief affects them while $81(21.3 \%)$ do not, $171(50.2 \%)$ agrees that they always forget to take their routine drugs, while $190(49.8 \%)$ do not, 50(13.1) said fear of taking too many drugs affects them while $331(86.9 \%)$ did not, $290(76.1 \%)$ said they are tired of taking the routine drugs while $91(23.9 \%)$ do not, and $331(86.8 \%)$ said attitudes of health care providers affects them while $50(13.2 \%)$ did not agree.

\section{DISCUSSION OF FINDINGS}

Findings from this study showed that most (67.9) of the respondents were between the ages of $21-30,46.7 \%$ were $4-6$ gestational age, $49.6 \%$ had secondary certificate holders, $41.5 \%$ were traders while majority $(53.5 \%)$ were Islam.

The results from this study revealed that $(91.3 \%)$ of the respondents knows about routine drug supplementation in pregnancy with Iron (fersolate) $(94.4 \%)$, Folic acid (91.8\%), Vitamin D (52.5\%), Vitamin A (80.1\%) and Vitamin C $(86.6 \%)$ as routine drugs (micronutrients) in pregnancy. This result agrees with the findings of Oladipo; Falana; Adegoke; Sambo \&Kungu (2015) on Prevalence of anemia among pregnant women and its determinants in the 4 Northern Nigerian states of Jigawa, Katsina, Yobe and Zamfara using a cross sectional design a total of 628 pregnant and post-partum women revealed that $79.7 \%$ of the respondent were aware of the benefits of seeking ANC, Less than 50\% reported consuming IFA $\geq 90$ days. Utilization of IFA among pregnant women was affected by such factors as misconception about IFAS, influences of male spouse and senior female family members.

Also findings from this study showed that most (74.0\%) of the respondents use routine drugs and $(65.6 \%)$ use them on daily basis. This result is in consonant with the findings of Gebremedhin, Samuel, Mamo, Moges\&Assefa (2014) on evaluating the Coverage, compliance and factors associated with utilization of iron supplementation during pregnancy in eight rural districts of Ethiopia using a cross-sectional study revealed that among pregnant women who were given/prescribed supplements, the average level of compliance was $74.9 \%$. The leading reported reasons for non-adherence were side-effects $(63.3 \%)$ and forgetfulness $(16.7 \%)$. Also study conducted by Dietary supplementation usage by pregnant women in Silesia - population based studyKnapik A, Kocot K, Witek A, Jankowski M, Wróblewska-Czech A,Kowalska M, Zejda JE, Brożek G (2018) on Dietary supplementation usage by pregnant women in Silesia - population based study with a sample size of 505 revealed thatmicro-minerals and vitamins supplementation during pregnancy was declared by $410(81.2 \%)$ women. The most often used supplement was folic acid (62\%). More than one-third of pregnant women $(38.4 \%)$ declared vitamin D intake. Among the recommended supplements, the least commonly used $(30.3 \%)$ were polyunsaturated fatty acids (PUFA). Factors contributing to supplementation use during pregnancy are past history of miscarriage and socioeconomic factors, such as: place of residence, financial situation and level of education. Inhabitants of larger cities, women with better self-perceived financial situations, higher education levels and those presenting past history of miscarriage took the supplements significantly more often

Also, findings of Oriji, Enyindah, Nyeche(2011) on factors determining compliance to routine iron supplementation in pregnancy at the University of Port Harcourt Teaching Hospital. A total of five hundred antenatal clients were recruited randomly during their antenatal visits between 1st May and 30th June, 2009 at the UPTH showed that overall compliance in the study was $88.0 \%$. Women who complied fully were of the perception that good blood level and birth weight were beneficial effects of the routine iron supplement. Gastrointestinal side effects and forgetfulness were the main reasons for low compliance. But is not in consonant with the findings of Gebrel, Mulugeta, and Etana (2014) assessed the factors Associated with Adherence to Iron-Folic Acid Supplementation among Urban and Rural Pregnant Women in North Western Zone of Tigray, Ethiopia. An institution based comparative cross sectional study was employed among 358 urban and 356 rural pregnant women attending antenatal clinics in North Western Zone of Tigray from March to April 2014 which Showed that the rate of adherence to iron folic acid supplementation among the pregnant women in the urban and rural communities was $37.2 \%$ $(95 \% \mathrm{CI}, \quad 32.26 \%-42.25 \%)$ and $28.9 \% \quad(95 \% \mathrm{CI}$, $24.4 \%-33.81 \%$ ) respectively indicating that there was no significant difference among the two groups with regard to adherence to iron-folic acid supplementation. And findings of Bekele, Gedefaw\&, Alemtsehay (2015) carried out a study to determine the factors associated with compliance of prenatal iron folate supplementation among women in Mecha district, Western Amhara, Ethiopia. Community based cross sectional study design was employed in Mecha district from June 25 July 15/2013 with a sample of 634 women who gave birth 12 months before the survey was included in the study revealed that only $20.4 \%$ of participants were compliant with iron foliate supplementation. Belief that too many tablets would harm the baby and fear of side effects were the major reasons given for noncompliance.

Findings from this study showed that fear of side effects of drugs $(52.5 \%)$, cultural belief $(78.7 \%)$, and forgetfulness $(50.2 \%)$, tired of taking the routine drugs $(76.1 \%)$ and attitudes of health care providers $(86.8 \%)$ were the factors as reported by the respondents that affects their use of routine drugs supplementation in pregnancy. This result is in line with result of $\underline{\mathrm{Ugwu}}, \underline{\text { Olibe, }} \underline{\mathrm{Obi}}, \& \underline{\mathrm{Ugwu}}$, (2014) on evaluated the determinants of compliance to iron supplementation among pregnant women in Enugu, Southeastern Nigeria using a questionnaire-based cross-sectional descriptive design in a sample of 302 eligible pregnant women receiving antenatal care at the University of Nigeria Teaching Hospital (UNTH), Ituku/Ozalla, Enugu, Nigeria between April 1, 2012 and January 31, 2013 which revealed that $\operatorname{most}(76.3 \%)$ of the respondents have good knowledge of iron supplementation and majority(65.9\%) complied with the use of iron supplement The major barriers to compliance to iron supplementation included 
gastrointestinal side effects of iron supplements (41.7\%), non-affordability of iron supplements (28.3\%), and forgetfulness $(15.0 \%)$ among the antenatal mothers. Also agree with the findings of Bekele, Gedefaw\&, Alemtsehay (2015) on the factors associated with compliance of prenatal iron folate supplementation among women in Mecha district, Western Amhara, Ethiopia. Community based cross sectional study design was employed in Mecha district from June 25 July 15/2013 with a sample of 634 women who gave birth 12 months before the survey was included in the study showed that Only $20.4 \%$ of participants were compliant with iron foliate supplementation. Belief that too many tablets would harm the baby and fear of side effects were the major reasons given for noncompliance.

\section{CONCLUSION}

Based on the findings from this study, the researchers concluded that the participants have significant knowledge of routine micronutrient supplementation in pregnancy and adhere to the use of the routine drugs. Fear of side effects of drugs, cultural belief, forgetfulness, tired of taking the routine drugs and attitudes of health care providers are factors that affect their use of routine drugs in pregnancy.

\section{Recommendations}

1. Health personnel should place more emphasize on explaining the danger associated with non-compliance to the use of routine micronutrients supplements on their developing fetus and baby during health education at antenatal visit.

2. Health personnel should be friendly to women on antenatal visit as this will enhance their use of routine micronutrients supplements

3. Health personnel should also educate the women by letting them know that routine micronutrient supplements have little or no side effects neither on them or their fetus/babies.

4. Government should always ensure that routine micronutrient supplements are readily available, accessible and affordable to all women of child bearing age.

\section{REFERENCES}

[1] Afam A.O, Nkwam.C. Uwaoma (2012): Nutritional and Psychological Implications of Low Micro-Nutrient Status of Pregnant Women in Imo State, Nigeria. Studies in Sociology of Science , 3 (1), 29-34. Retrieved from http://dx.doi.org/10.3968/j.sss.1923018420120301.028 on 15th September, 2015 .

[2] Bekele T., Gedefaw A. \&Alemtsehay M. (2015): Factors associated with compliance of prenatal iron folate supplementation among women in Mecha district, Western Amhara: a cross-sectional study. Pan African Medical Journal.http://www.panafrican-med-journal.com/content/article/20/43/ full/

[3] Black RE, Allen LH, Bhutta ZA, Caulfield LE, de Onis M, Ezzati M, et al. (2008): Maternal and Child Undernutrition. Lancet371:243-260. Retrieved from http:/www.ncbi.nlm.nih.gov/entrez/eutils/elink.fcgi? on 13th May, 2015

[4] ElshiblyE.M,\&Schmalisch G. (2008):The effect of maternal anthropometric characteristics and social factors on gestational age and birth weight in Sudanese newborn infants. BMC Publ Health 2008, 8:244.

[5] Darnto-Hill I, Mkparu U.C (2015): micronutrients in pregnancy in low and middle income
[6] De ver Dye T, Pelto G, kristenson S, Samen A, Dozier A (2015): Attitudes and Practices towards Micronutrient Supplementation among Pregnant Women in Rural Tibet. Glob Public Health; 10(1): 119-129

[7] Desta M, Kassie B, Chanie H, Mulugeta H, Yirga T, Temesgen H, Leshargie CT, Merkeb Y (2019): Adherence of iron and folic acid supplementation and determinants among pregnant women in Ethiopia: a systematic review and meta-analysis. Reprod Health;16(1):182.

[8] GebremedhinS, SamuelA, MamoG,MogesT\&AssefaT (2014) Coverage, compliance and factors associated with utilization of iron supplementation during pregnancy in eight rural districts of Ethiopia: a cross-sectional study. BMC Public Health 2014, 14:607

[9] Gebre1 A, Mulugeta A, Etana B. (2015): Assessment of Factors Associated with Adherence to Iron-Folic Acid Supplementation Among Urban and Rural Pregnant Women in North Western Zone of Tigray, Ethiopia. International Journal of Nutrition and Food Sciences.(http://www.sciencepublishinggroup.com/j/ijnfs)

[10] Kawai K, spiegelman D, shanker A.H, fawzi W.W (2011): Maternal Multiple Micronutrient Supplementation and Pregnancy Outcomes in Developing Countries. Meta-analysis and Meta-regression. Bull world health organ; 89(6): 402-411

[11] Knapik A, Kocot K, Witek A, Jankowski M, Wróblewska-Czech A, Kowalska M, Zejda JE, Brożek G. Dietary supplementation usage by pregnant women in Silesia - population based study. Ginekol Pol. 2018;89(9):506-512.

[12] Nechitilo M. A (2014): A qualitative study of factors influencing adherence with micronutrient supplementation among women of reproductive age in Viet Nam. Emory University Theses and Dissertation Repository.http://etd.library.emory.edu/view/record/pid/emory:g1q8t

[13] Oladipo A. R,Falana A. O,Adegoke O, Sambo A \&Kungu J (2015):Prevalence of anemia among pregnant women and its determinants Northern Nigerian. Micronutrient Initiative.www.micronutrient.org/wp-content/uploads/2015/05/0318.p df

[14] Oriji V. K, Enyindah C. E,\&Nyeche S. (2011): Factors determining compliance to routine iron supplementation in pregnancy at the University of Port Harcourt Teaching Hospital. Nigerian Journal of Medicine ;20:131-4.

[15] Roy .A; Evers S. E. \& Campbell M. K. (2012):Dietary supplement use and iron, zinc and folate intake in pregnant women in London, Ontario Chronic Diseases and Injuries in Canada Volume 32, no. 2.

[16] Taddese A.Z. \&Henok T.A. (2013): Micronutrient deficiencies result from inadequate intake of meat, fruits and vegetables, and infections can also be a cause. ( Micronutrients and pregnancy; effect of supplementation on pregnancy and pregnancy outcomes: a systematic review. Nutritional Journal retrieved from http://www.nutritionj com/content/12/1/20 on 13th May, 2015

[17] Thirukkanesh S \&Zahara A.M. (2010): Compliance to Vitamin and Mineral Supplementation among Pregnant Women in Urban and Rural Areas in Malaysia. Pakistan Journal of Nutrition 9 (8): 744-750

[18] Ugwa E.A. (2015) Vitamin C supplementation in pregnancy: A review of current literature Nigerian Journal of Basic and Clinical Sciences.Vol 12 Issue 1 1-5. Retrieved from http://www.njbcs.net/article.asp on 13th May, 2015

[19] World Health Organization. Food and Agricultural Organization of the United Nations. (2014): Vitamin and mineral requirements in human nutrition, 2nd ed. Geneva, World Health Organization. (http://www.who.int/nutrition/publications/micronutrients/ 9241546123/en/index.html. Retrieved 29th April, 2015).

[20] WHO (2013): Guideline: Calcium supplementation in Pregnant Women. www.who.int. retrieved May 10th, 2015 